\title{
Analysis and Experimental Study on Bearing Capacity of “All-Inclusive" Underpinning Joint
}

\author{
Kefeng Yue (iD) and Lei Yan (iD) \\ School of Civil Engineering, Chongqing Three Gorges University, Chongqing, China \\ Correspondence should be addressed to Lei Yan; yanlei1988413@163.com
}

Received 4 August 2019; Revised 17 November 2019; Accepted 6 January 2020; Published 12 March 2020

Academic Editor: Chun-Qing Li

Copyright (C) 2020 Kefeng Yue and Lei Yan. This is an open access article distributed under the Creative Commons Attribution License, which permits unrestricted use, distribution, and reproduction in any medium, provided the original work is properly cited.

\begin{abstract}
Aiming at the phenomenon of punching failure and large slip at the new-to-old concrete interface of "beam-column" underpinning joint, a new type of "all-inclusive" underpinning joint is tested and numerically analyzed, which adopts the spraying glue + grooving + planting bars + prestressed + hooping connection method. The experimental and numerical analysis results show that the connection method of "all-inclusive" underpinning joint can effectively avoid punching failure of the joint, and the failure mode is mainly flexure-shear. Then, the "all-inclusive" underpinning joint can delay the initial slip at the new-to-old concrete interface and reduce the overall slip. Finally, combining the theoretical and experimental results, a simplified calculation formula for the bearing capacity of the "all-inclusive" underpinning joint is improved. The theoretical results are in good agreement with the experimental results, which indicates that the calculation of the bearing capacity of the underpinning joint using the formula in this paper is feasible and can provide experimental and theoretical references for similar projects.
\end{abstract}

\section{Introduction}

Underpinning technology is the core construction technology for developing underground space of existing buildings, which is applied to underpinning, rectifying, expanding, and displacing buildings or structures, and the "beam-column" connection method and "all-inclusive" connection method are main connection methods of underpinning joints $[1,2]$. Both methods have been tested and analyzed on the bearing capacity of underpinning joints. In the 1950s, the underpinning technology of pile foundation was applied in Germany, which has been included in industrial standard [3]. In the 1960s, the "beam-column" underpinning technology was adopted in Japan's Kyoto subway for the first time, and then the "beam-column" connection method was widely used [4]. In 2003, the "beamcolumn" underpinning joint adopting the planting bar + prestressed method was first used in the subway project of Shenzhen, and the slip value of underpinning joint was controlled well [5]. In 2008, using the "beam-column" underpinning method, two columns of the Tianjin underpinning project were successfully underpinned for the first time [6]. In 2011, five similar underpinning joints adopting the "beam-column" underpinning method were tested, the connection method of roughening + planting bar + prestressed was adopted, and a formula for calculating the bearing capacity of underpinning joint was first put forward [7, 8]. In 2015, a pile underpinning technology was proposed for shield tunnel cross through group pile foundation, and a series of theoretical analysis and numerical simulation were carried out to explore the load transfer mechanism of a bridge structure [9]. In 2015, based on the underpinning project of a subway tunnel, a new type of "allinclusive" model tests were carried out. The results showed that the stirrup reinforcement ratio and planting bar played a major role in the shear resistance of the new-to-old surface [10]. In 2016, a large number of "beam-column" underpinning joints were numerically analyzed and found that bearing capacity was provided by the bonding force provided by the new-to-old concrete interfaces, the friction force provided by the hooping-force on all sides, and the interface friction force provided by the prestressed force 
[11]. In 2017, sixteen "beam-column" underpinning joints were analyzed, considering different shear span-to-depth ratios, underpinning joint heights, reinforcement ratios, and so forth. The experimental results showed that the bearing capacity can be greatly improved by decreasing the shear span-to-depth ratio [12].

A number of research studies have been done on "beamcolumn" underpinning joints, but not on "all-inclusive" underpinning beam joints. Therefore, in this paper, a new type of "all-inclusive" underpinning joint adopting the connection method of roughening + planting bar + prestressed + building glue + hooping was tested and analyzed to discuss the bearing mechanism of underpinning joint, and so as to provide experimental and theoretical support for similar projects.

\section{Test Design}

2.1. Model Making. This paper studies the large-axis underpinning joint relying on a domestic international airport underground railway line to pass through the airport main line bridge. As shown in Figure 1, the newly built tunnel line passes through the pile foundation of the existing main line pier, and the project needs to stably transfer the load of the upper structure through the special design of the underpinning structure to obtain more underground space for tunnel construction. The data show that the underpinning joint has a length of $20 \mathrm{~m}$ and an underpinning axial force of $13000 \mathrm{kN}$ and adopts the "all-inclusive" pile foundation, i.e., the connection form in which the beam joint wraps the bearing platform and some piles inside the underpinning joint. Due to the large size of the structure, the model test is considered to be conducted on a scale of $1: 6$.

According to the scale of $1: 6$, the model test (ZT-1) research and numerical analysis (MT-1 and MT-2) are carried out, respectively. MT-1 is a numerical model completely consistent with the relevant parameters of ZT-1, MT-2 is a cast-in-situ overall numerical model with the same parameters as ZT-1, and the size parameters of test pieces are shown in Table 1. After the pile foundation has been made, firstly, roughening and planting steel bars on the side of the pile foundation are performed; then, assembling reinforcements on the outer side of the pile foundation and spraying building glue are done; finally, making and prestressing of the underpinning beam are done. The prestressed steel bar adopts the high strength and low relaxation $\Phi^{\mathrm{s}} 1860$ steel strand and is equipped with 5 strands ( 2 strands on the upper edge and 4 strands on the lower edge) and anchored by clamp anchorage of corresponding specifications. The underpinning beam diagram is shown in Figures 2 and 3, the steel bar diagram is shown in Figures 4 and 5, and the test piece is shown in Figures 6 and 7.

2.2. Material Property Test. In this test, the concrete of foundation and underpinning beam are of C35 and C50. Before the test, the strength and material properties of the concrete $150 \mathrm{~mm}$ cube test block are tested. The steel bar adopts the HRB335 steel bar, and the pull-out test is conducted before test loading, and the material performance

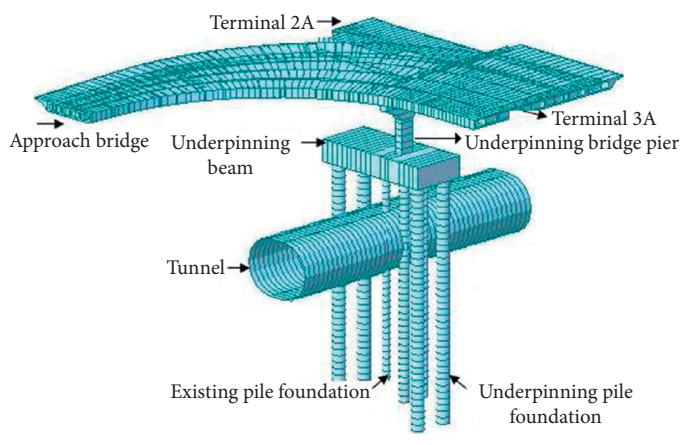

FIgURE 1: Diagram of underpinning project.

meets relevant specifications. The prestressed steel bar adopts the $\Phi^{\mathrm{s}} 1860$ steel strand with high strength and low relaxation, and its mechanical properties meet the provisions of relevant national standards. The mechanical properties of the materials are shown in Tables 2 and 3.

2.3. Loading Method. Loading system: test data are acquired by using the $500 \mathrm{~T}$ hydraulic loading system and static data acquisition system. Loading method: the repeated progressive static loading method of loading-unloadingreloading is adopted, and the specimens are loaded according to load control and displacement control, respectively, before and after yielding. Loading step: during load control, first, carry out $150 \mathrm{kN}$ preload test twice and then apply repeated load with $200 \mathrm{kN}$ as the first level until the specimen yields. After yielding, the specimen is subjected to displacement control, with 0.5 times the maximum yield displacement value $(0.5 \delta)$ as the first stage of loading, and each stage is repeated 3 times until the specimen is damaged.

2.4. Layout of Measuring Points. The measuring points: the underpinning girder is divided into seven sections, i.e., the supporting points on both sides, the new-to-old concrete interfaces on the left and right of the bearing platform, the lower part of the action point, and the $1 / 4$ and $3 / 4$ of beam spans. The steel strain gauges are arranged at the longitudinal reinforcement and the making stirrups at the corresponding sections. The displacement gauges and concrete strain gauges are arranged at the bottom of the beam at the corresponding sections above. There are 58 steel strain gauges, six concrete strain gauges, and eight displacement gauges. The location of the measuring points is shown in Figure 8.

\section{Test Results}

3.1. Analysis of Test Phenomena. The fracture diagram of the test model is shown in Figures 9-12. At the initial stage of test loading, the load is controlled. At $550 \mathrm{kN}$, the first $100 \mathrm{~mm}$ transverse crack appeared at the bottom of the beam. At $1500 \mathrm{kN}$, cracks appeared at the bottom of the beam and developed everywhere and two oblique cracks appeared at the bearing in the direction of 45 to the loading point. The interface between the new and old concrete of the underpinning beam was well bonded. At $2000 \mathrm{kN}$, the crack 
TABLe 1: Dimension parameters.

\begin{tabular}{lccccccc}
\hline Model & Beam size $(\mathrm{mm})$ & $\begin{array}{c}\text { Chisel depth } \\
(\mathrm{mm})\end{array}$ & $\begin{array}{c}\text { Grooving size } \\
(\mathrm{mm})\end{array}$ & $\begin{array}{c}\text { Planting bar } \\
\text { diameter }(\mathrm{mm})\end{array}$ & $\begin{array}{c}\text { Prestressed } \\
\text { area }\left(\mathrm{mm}^{2}\right)\end{array}$ & $\begin{array}{c}\text { Hoop } \\
(\%)\end{array}$ & $\begin{array}{c}\text { Reinforcement } \\
(\%)\end{array}$ \\
\hline ZT-1 & $3383 \times 1450 \times 583$ & 20 & $100 \times 50$ & 16 & 5580 & 0.49 & 2.8 \\
MT-1 & $3383 \times 1450 \times 583$ & 20 & $100 \times 50$ & 16 & 5580 & 0.49 & 2.8 \\
MT-2 & $3383 \times 1450 \times 583$ & - & - & - & 5580 & 0.49 & 2.8 \\
\hline
\end{tabular}

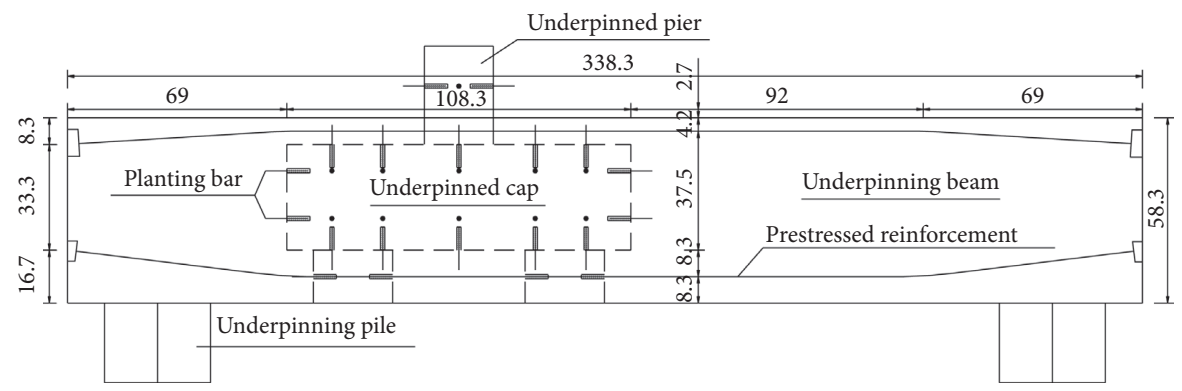

Figure 2: Side view of underpinning beam $(\mathrm{cm})$.

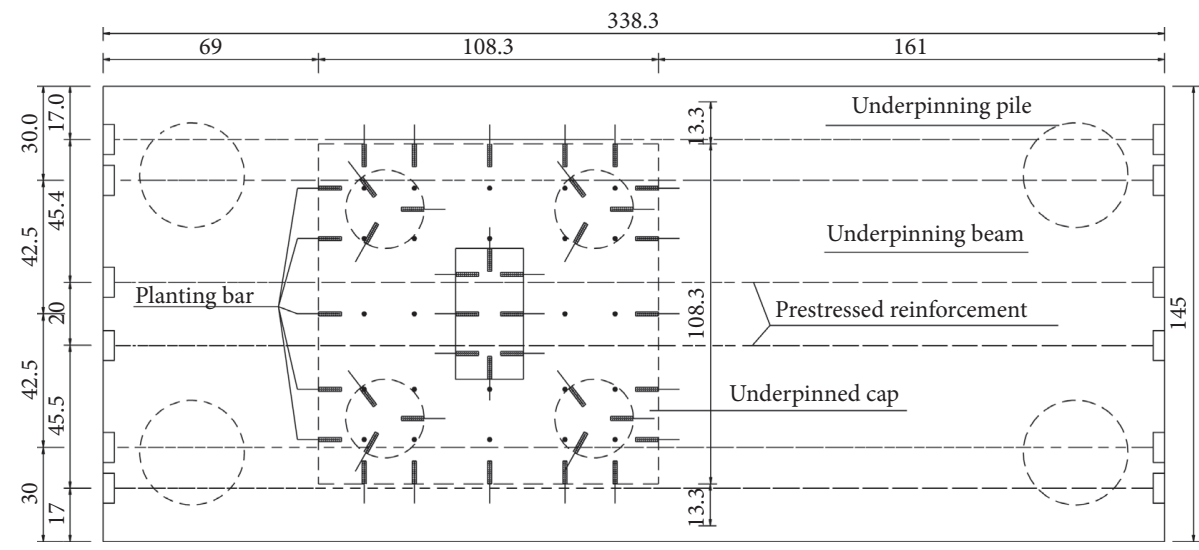

Figure 3: Plan view of underpinning beam $(\mathrm{cm})$.

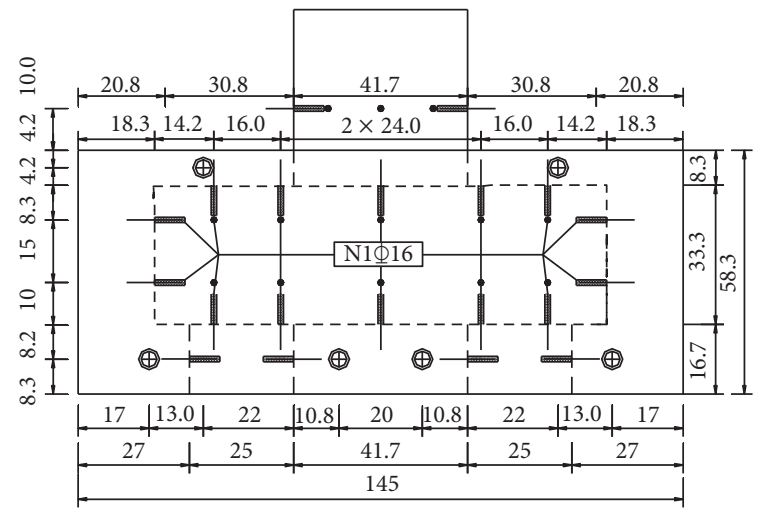

FIgure 4: Planting bars drawing $(\mathrm{cm})$.

at the bottom of the beam forms a grid in the transverse direction and extends to the width direction of the beam, with the width of the crack being $0.1 \mathrm{~mm}$. The main oblique fractures on the north side continue to extend obliquely and tend to be horizontal, with a width of $0.15 \mathrm{~mm}$ and a length of $400 \mathrm{~mm}$. At $2500 \mathrm{kN}$, the underpinning beam enters the yield state and is changed to displacement control loading.

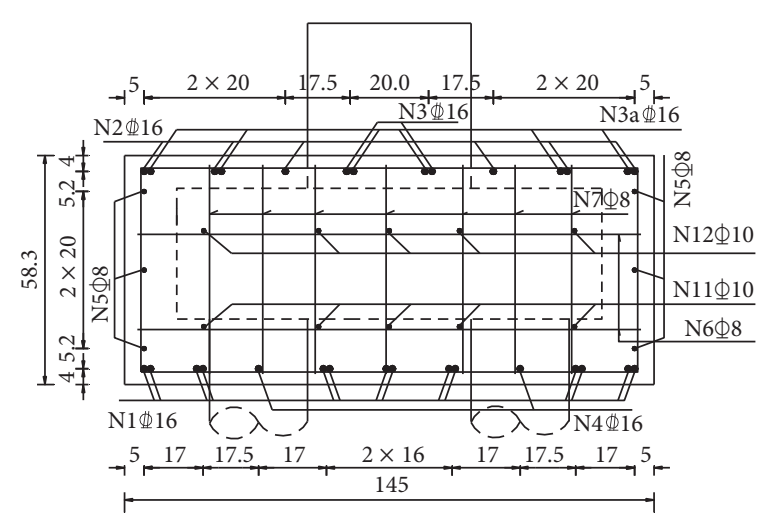

Figure 5: Reinforcement drawing (cm).

At this moment, the load increases slowly and the displacement increases obviously. The cracks are found at the bottom of the beam, which extend from the bottom to the side of the beam with a width of $0.2 \mathrm{~mm}$, and some transverse cracks appear at the top of the beam. When the load continues to $2750 \mathrm{kN}$, the crack on the side of the specimen is distributed in an arch shape, and then the 


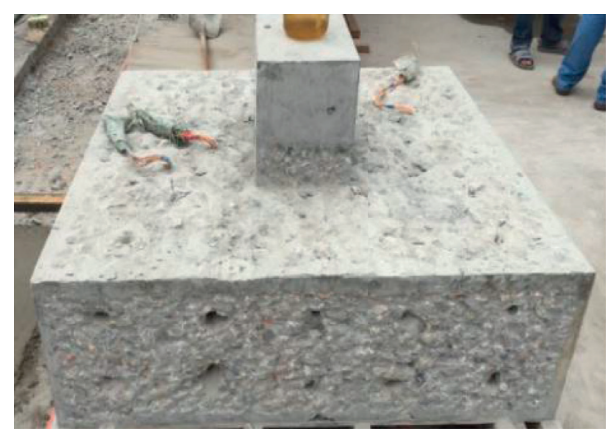

FIgURE 6: Planting bars diagram of pile foundation.

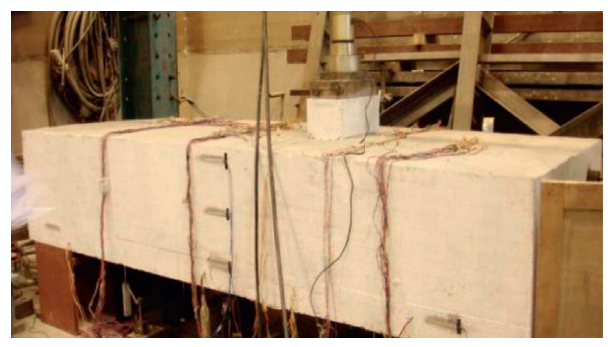

Figure 7: Specimen diagram.

TABLE 2: Mechanical properties of steel bars.

\begin{tabular}{lccccc}
\hline Category & Test method & Yield strength $(\mathrm{MPa})$ & Ultimate strength $(\mathrm{MPa})$ & Elongation $(\%)$ & Elastic modulus $(\mathrm{MPa})$ \\
\hline Reinforcement & Field test & 342 & 459 & 6.2 & $2 \times 10^{5}$ \\
Prestressed steel & Field test & 1738 & 1875 & 3.5 & $1.95 \times 10^{5}$ \\
\hline
\end{tabular}

TABle 3: Mechanical properties of concrete (MPa).

\begin{tabular}{lll}
\hline Strength grade of concrete & C35 & C50 \\
\hline Average & 36.3 & 52.2 \\
Standard & 29.5 & 43.6 \\
\hline
\end{tabular}

bearing capacity starts to decline rapidly. When the underpinning beam is damaged, the maximum deflection is $16.9 \mathrm{~mm}$, the maximum crack width on the beam side is $0.2 \mathrm{~mm}$, and the main crack forms an arch.

The bearing capacity and failure modes of the specimens are shown in Table 4. From phenomena and analysis of results, the failure mode of the specimens is flexure-shear and no interface punching failure occurs. Combined with the analysis of specimen crack morphology, we found that the jacking effect at the bottom of the beam makes the underpinning beam and the bearing platform connected well, and the mechanical failure mode of the underpinning beam basically conforms to the characteristics of cast-in-situ integral concrete beam, which indicates that the connection mode of "all-inclusive" pile foundation underpinning joint can effectively avoid punching failure and has greater underpinning bearing advantages.

3.2. Stress and Displacement Analysis. Figure 13 shows a load-displacement hysteretic curve of the specimen M1-1. In the load-slip curve of underpinning beam joint, the ratio of ultimate displacement of the underpinning beam joint to initial slip displacement of the beam joint when the underpinning beam is damaged is usually defined as ductility ratio [5]:

$$
\lambda=\frac{\Delta_{\mathrm{u}}}{\Delta_{0}}
$$

According to the definition of ductility ratio, the greater the ductility ratio, the better the ductility and integrity of underpinning beam joints. According to Figure 13 and Table 4, the load-displacement curve of the ZT-1 underpinning beam has obvious yield deformation stage, and the ductility ratio of the specimen reaches 7.7, which is larger than that in the previous studies $[5,12]$. Further, the relative slip amounts mentioned in the previous studies $[5,12]$ are $0.3 \mathrm{~mm}$ and $0.4 \mathrm{~mm}$, respectively, under the same conditions of "beam column", which are much larger than the relative slip amounts of ZT-1 in this paper. Therefore, it can be seen that the initial slip and the overall slip at the new-to-old concrete interface can be effectively reduced by adopting the "all-inclusive" underpinning joint.

Figure 14 is the strain diagram of longitudinal reinforcement at the interface between the new and old concrete and at sections $1 / 4,1 / 2$, and $3 / 4$. The maximum point of bending moment with the fastest strain growth is directly below the loading point, followed by the joint of the left and right interfaces of the bearing platform. The strain growth of reinforcement in other sections is relatively small. Moreover, 


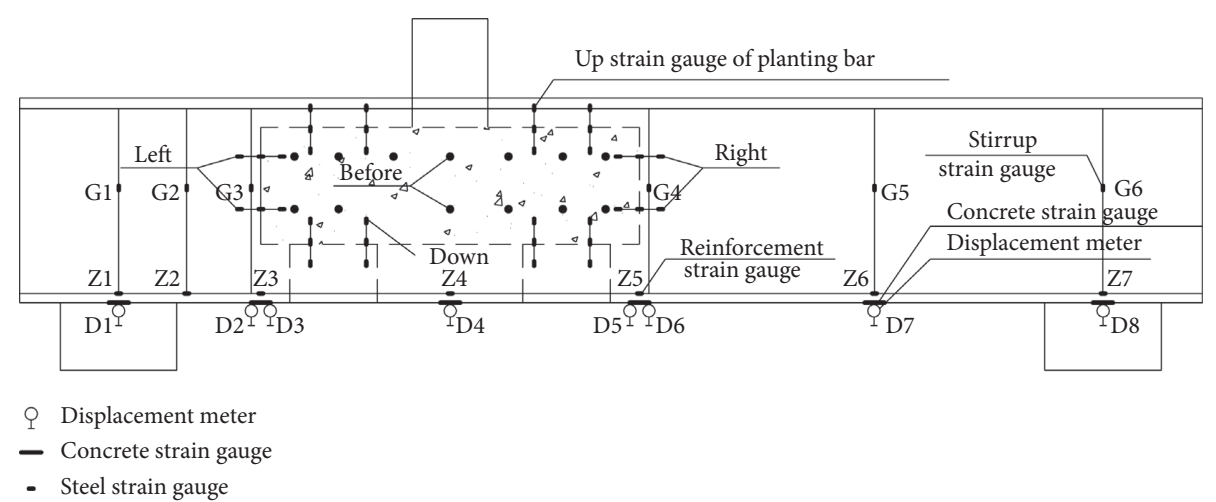

Figure 8: Measuring points.

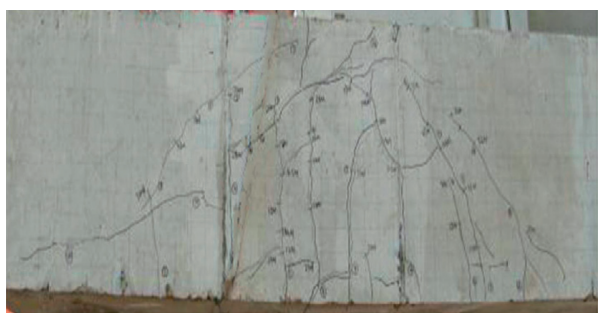

FIGURE 9: Crack diagram of north side.

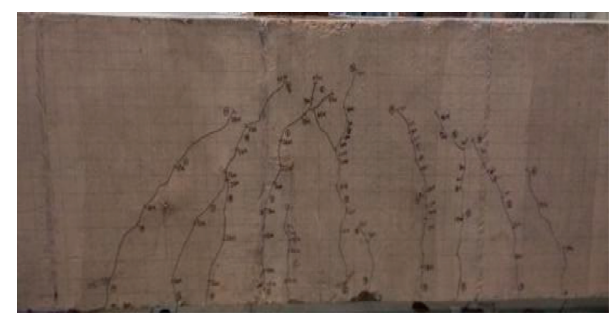

Figure 10: Crack diagram of south side.

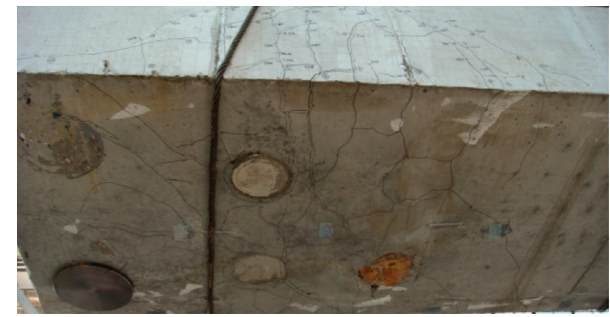

FIGURE 11: Crack diagram of bottom.

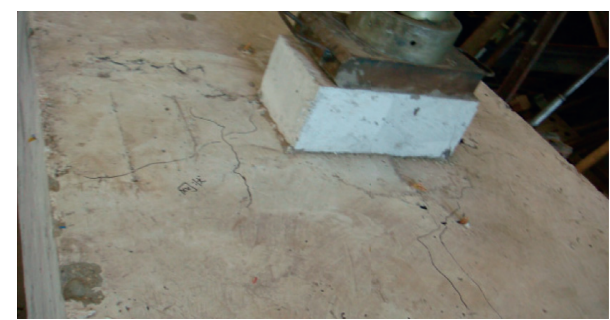

FIGURE 12: Crack diagram of top. at $1500 \mathrm{kN}$, the longitudinal reinforcement strain at the interface between the new and old concrete has obvious abrupt change, but the longitudinal reinforcement at the maximum point of bending moment yields first and then the longitudinal reinforcement at the interface between the new and old concrete. Therefore, the final failure of the underpinning joint is due to bending and shear failure caused by yield of longitudinal reinforcement instead of punching and sliding failure of the interface.

Figure 15 shows the load-strain relationship of stirrups of the underpinning joint at the new-to-old concrete interface and at sections $1 / 4,1 / 2$, and $3 / 4$. The stirrup strain changes are obvious on the both sides of the new-to-old concrete interface, while the strain of other stirrups is smaller. When the load is small, the strain of all stirrups is small. When the load reaches $1500 \mathrm{kN}$, the stirrup strain at the new and old concrete interface has obvious abrupt change, but the strain of stirrups at other sections of the beam still increases slowly. Therefore, the making stirrups at the new-to-old interface of the underpinning joint participate in the shear resistance at the interface after the initial slip of the interface.

Figure 16 shows the strain curve of planting bars on the upper, lower, left, right, front, and rear surfaces of the foundation. The strain of planting bars on the upper, lower, front, and rear surfaces of the bearing platform is small during the whole loading process, indicating that planting bars on the upper and lower interfaces of the bearing platform and the outer cladding beam do not participate in shear resistance. In comparison, the planting bar strain on the left and right sides of the bearing platform changes greatly. When the load reaches $1500 \mathrm{kN}$, the planting bar strain on the left and right sides change abruptly, but the planting bars have not yet yielded when the specimen is damaged. Therefore, planting bars at the interface can provide greater shear resistance at the interface and can effectively avoid brittle failure such as punching failure of underpinning joint.

\section{Numerical Analysis}

4.1. Model Establishment. To analyze the results of the comparative test model further, the comparative model MT1 and the cast-in-place overall model MT-2 are established. 
TABLE 4: Bearing capacity and failure modes of specimens.

\begin{tabular}{lccccccc}
\hline Specimens & $P_{0}(\mathrm{kN})$ & $P_{\mathrm{u}}(\mathrm{kN})$ & $\Delta(\mathrm{mm})$ & $\Delta_{0}(\mathrm{~mm})$ & $\Delta_{\mathrm{u}}(\mathrm{mm})$ & $\lambda$ & Failure modes \\
\hline ZT-1 & 1480 & 2750 & 0.1 & 2.2 & 16.9 & 7.7 & Flexure-shear \\
Manuscript [5] & 1065 & 1825 & 0.3 & 3.4 & 13.5 & 4.0 & Flexure-shear \\
Manuscript [12] & 125 & 775 & 0.4 & 2.0 & 6.3 & 3.15 & Flexure-shear \\
\hline
\end{tabular}

$P_{0}$ is the initial slip load; $P_{\mathrm{u}}$ is the ultimate load; $\Delta$ is the relative slip displacement of the new-to-old concrete interface; $\Delta_{0}$ is the slip displacement of initial slip load; $\Delta_{\mathrm{u}}$ is the ultimate displacement of ultimate load; and $\lambda$ is the ductility ratio.

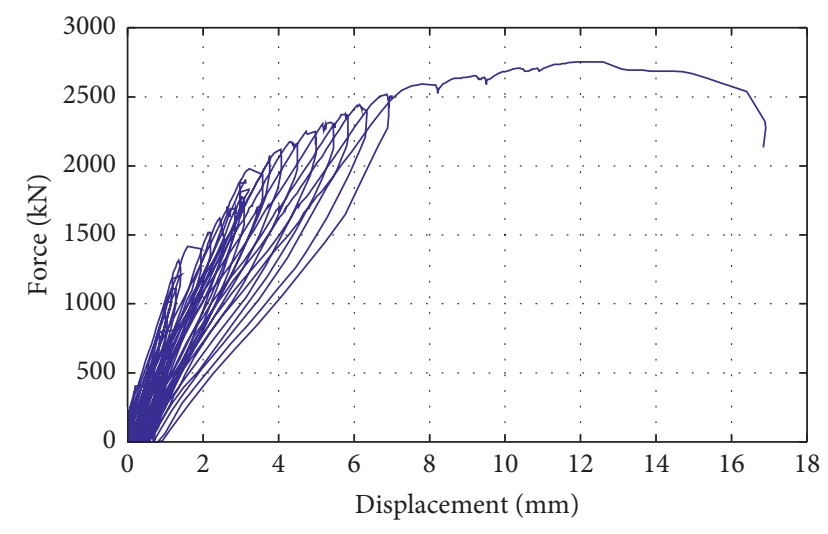

Figure 13: Load-displacement diagram.

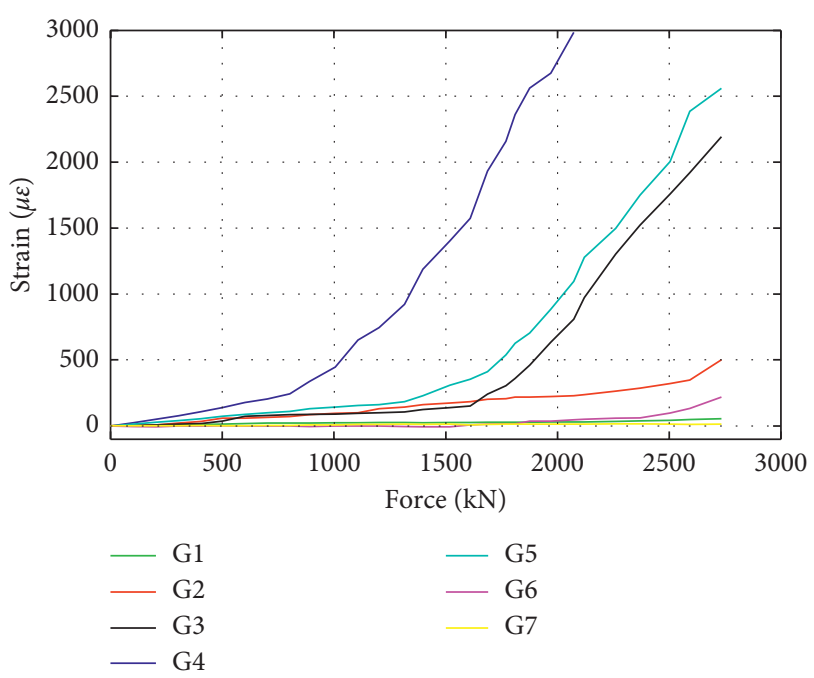

FIgURE 14: Strain diagram of longitudinal reinforcements.

Model-related dimension parameters have been given in Table 1. Three-dimensional elements (C3D8R) are used for concrete, and truss elements (T3D2) are used for reinforcement and embedded in concrete. The MT-1 model is shown in Figures 17-20.

As mentioned above, the concrete of the column and the beam are cast separately. Therefore, the contact properties of the new-to-old concrete interface of the underpinning joint need to be carefully considered, and the definition methods of contact attributes are briefly given based on normal behavior, tangential behavior, and cohesive behavior $[13,14]$.

The default relationship between contact pressure and clearance in normal behavior uses hard contact. When two

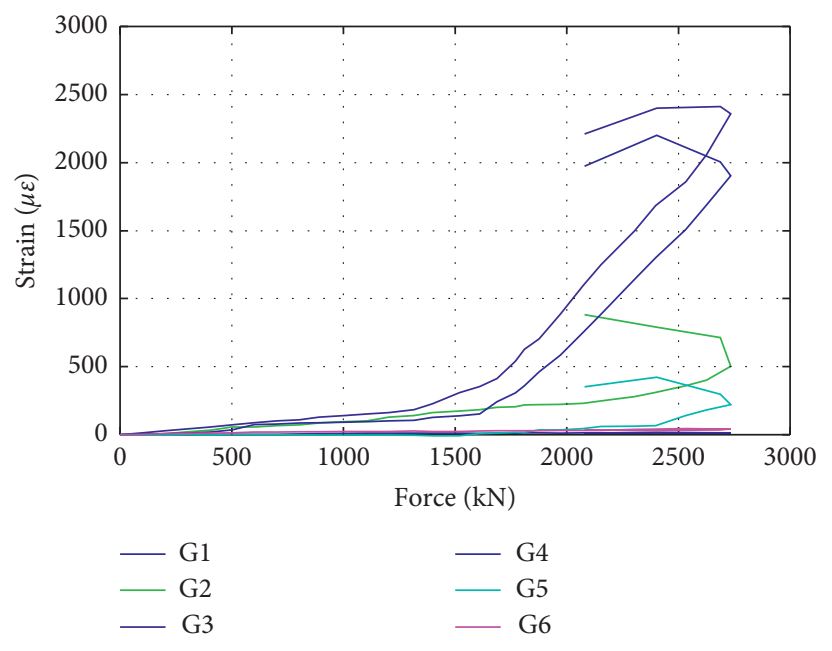

FIGURE 15: Strain diagram of stirrups.

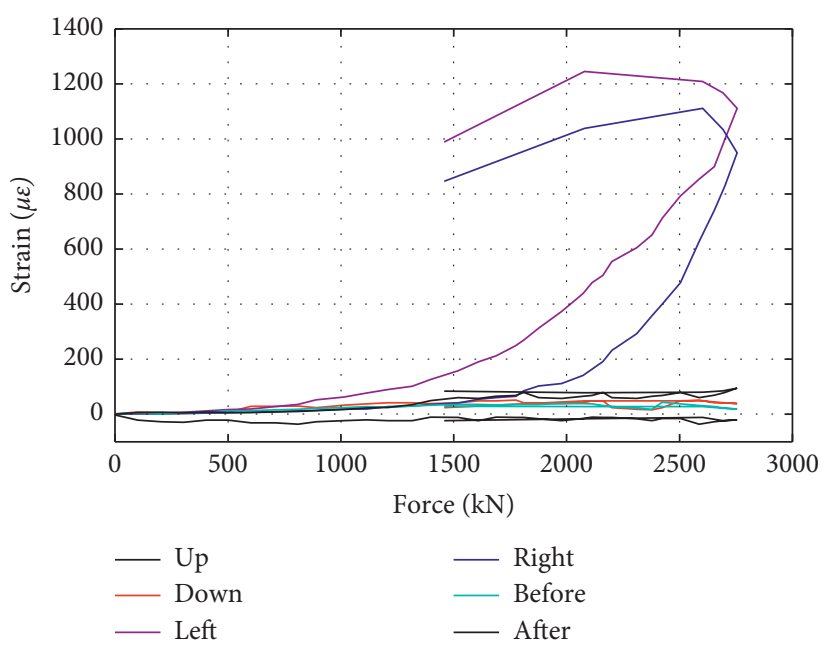

FIgURE 16: Strain diagram of planting bars.

surfaces are in contact, the magnitude of contact pressure that can be transferred between the contact surfaces is not limited. When the contact pressure becomes zero or negative, the two contact surfaces separate and the contact constraint on the corresponding joint is removed. The friction model of tangential behavior adopts the Coulomb model, i.e., friction coefficient is used to represent the friction characteristics between contact surfaces, and the default friction coefficient is zero, i.e., no friction. The calculation formula of Coulomb-friction is as follows:

$$
\tau_{\text {crit }}=\mu P \text {, }
$$




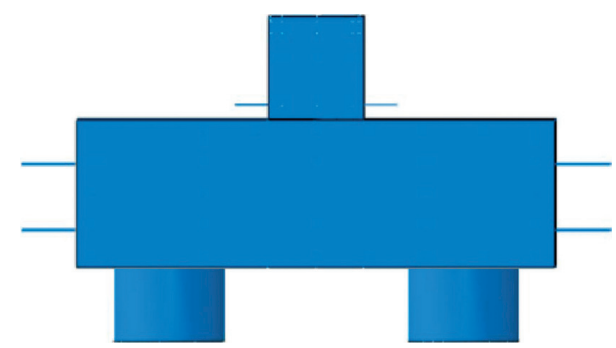

FIGURE 17: Foundation planting bar diagram of MT-1.

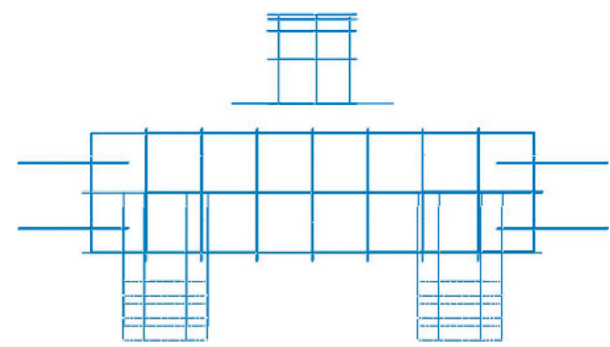

FIGURE 18: Reinforcement diagram of MT-1.

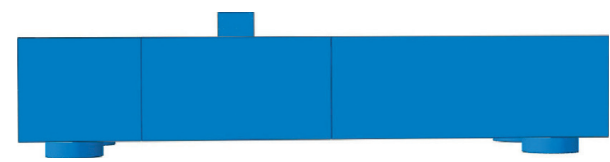

FIGURE 19: Underpinning beam diagram of MT-1.

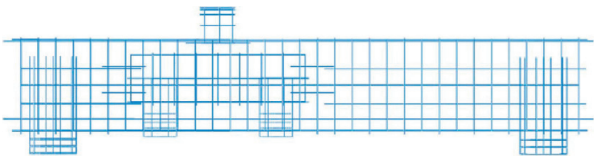

FIgUre 20: Steel bar diagram of MT-1.

where $\tau_{\text {crit }}$ is the critical shear stress, $\mu$ is the friction coefficient, and $P$ is the normal contact pressure.

The stress-displacement model element obeys linear elastic behavior before damage initiation and evolution of cohesive behavior. The cohesive elements are usually developed to describe interface, cohesion, or potential crack path. The behavior of cohesive elements is governed by the cohesive law, which defines the relation between cohesive stresses and crack opening or sliding displacements. Concrete destroying plastic damage model is mainly by the tensile and compressive equivalent plastic strain control. After strain softening point, the uniaxial tensile stress is expressed as equations (3) and (4) $[13,14]$ :

$$
\begin{aligned}
& \sigma_{\mathrm{t}}=\left(1-d_{\mathrm{t}}\right) E_{0}\left(\varepsilon_{\mathrm{t}}-\widetilde{\varepsilon}_{\mathrm{t}}^{p l}\right), \\
& \sigma_{\mathrm{c}}=\left(1-d_{\mathrm{c}}\right) E_{0}\left(\varepsilon_{\mathrm{c}}-\widetilde{\varepsilon}_{\mathrm{c}}^{p l}\right),
\end{aligned}
$$

where $\sigma_{\mathrm{t}}$ and $\sigma_{\mathrm{c}}$ indicate the tensile stress and compressive stress of the concrete after the softening point, respectively; $d_{\mathrm{t}}$ and $d_{\mathrm{c}}$ indicate the tensile damage parameter and compressive damage parameter, respectively; $\varepsilon_{\mathrm{t}}$ and $\mathcal{E}_{\mathrm{c}}$ indicate the tensile strain and compressive strain of the

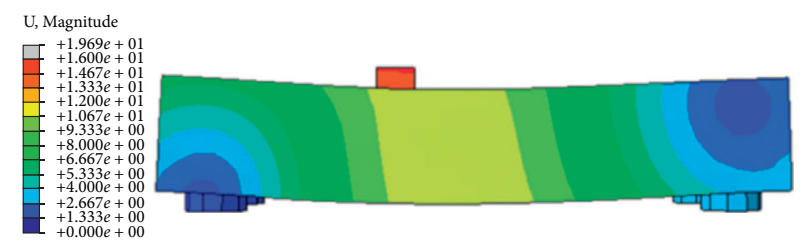

Figure 21: Displacement nephogram of MT-1.

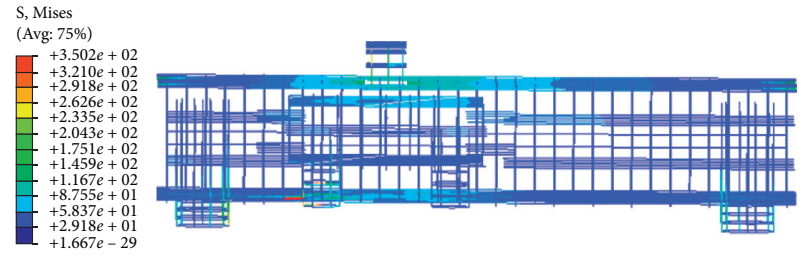

Figure 22: Steel bar stress nephogram of MT-1.

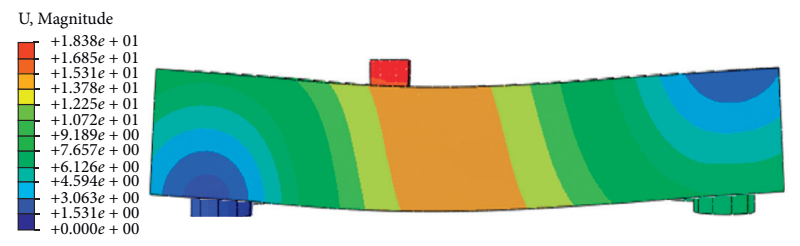

Figure 23: Displacement nephogram of MT-2.

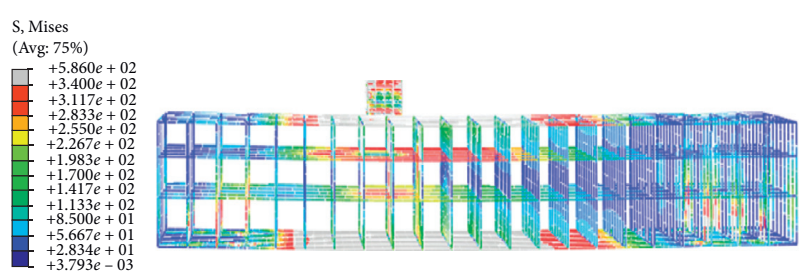

FIgURE 24: Steel bar stress nephogram of MT-2.

concrete after the softening point, respectively; and $E_{0}$ is the initial elastic modulus of the concrete.

4.2. Comparative Analysis of the Model and Test Results. The displacement nephogram and stress nephogram of MT-1 and MT-2 models are shown in Figures 21-24, and the bearing capacity and failure mode pairs of test and numerical models are shown in Table 5. The analysis shows that the destruction mode of the both models are flexure-shear, the load-displacement curve trend is relatively consistent, and the MT-1 results are in good agreement with ZT-1, which verifies the reliability of the test results. Further, the comparison of MT-1 and MT-2 loadslip curves in Figures 25-26 shows that the slip at the new-to-old interfaces is basically zero before failure, indicating that the "allinclusive" underpinning joint can achieve the bearing capacity of cast-in-situ integral concrete beams and can meet the design requirements of underpinning joint.

\section{Analysis of the Bearing Capacity of Underpinning Joints}

In the paper, a new type of "all-inclusive" underpinning joint model is designed. Comparing the experimental results with 
TABLE 5: Bearing capacity and failure modes of models.

\begin{tabular}{lccccc}
\hline Specimens & Initial slip load $(\mathrm{kN})$ & $\begin{array}{c}\text { Ultimate bearing capacity } \\
(\mathrm{kN})\end{array}$ & $\begin{array}{c}\text { Yield displacement } \\
(\mathrm{mm})\end{array}$ & $\begin{array}{c}\text { Ultimate displacement } \\
(\mathrm{mm})\end{array}$ & $\begin{array}{c}\text { Failure } \\
\text { modes }\end{array}$ \\
\hline ZT-1 & 1480 & 2750 & 2.2 & 16.9 & Flexure-shear \\
MT-1 & 1550 & 2690 & 2.4 & 19.7 & Flexure-shear \\
MT-2 & - & 2760 & 2.2 & 18.2 & Flexure-shear \\
\hline
\end{tabular}

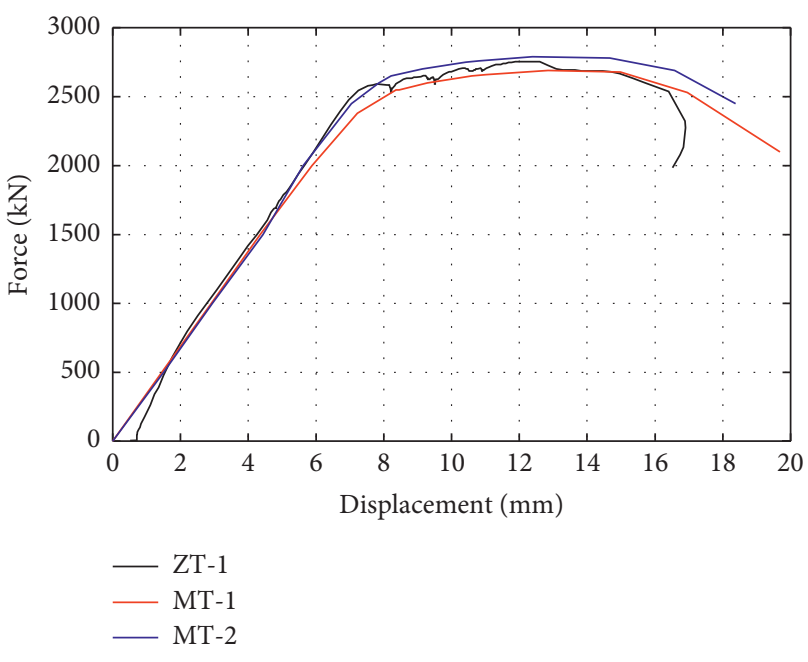

Figure 25: Load-displacement diagram.

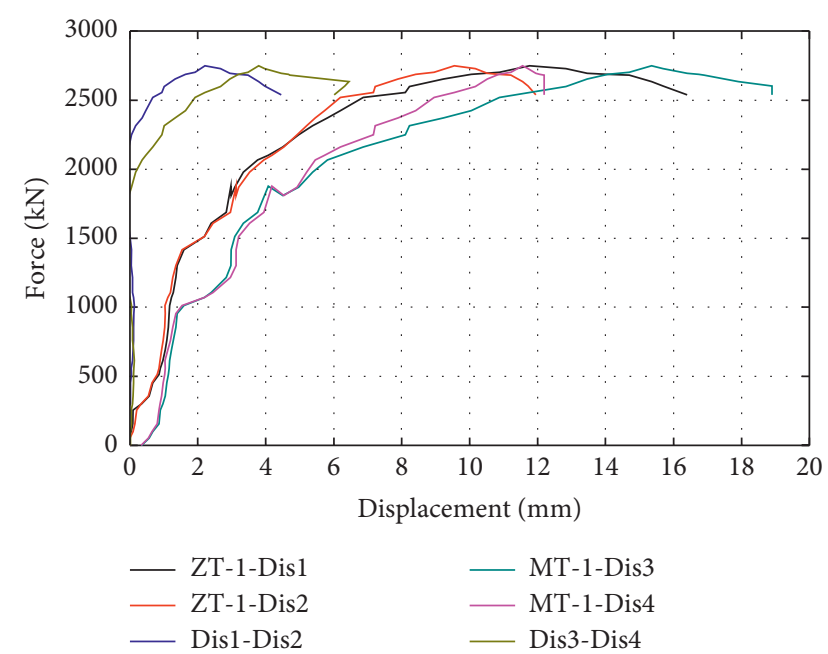

FIgURE 26: Load-slip diagram.

numerical results, the formula of European code [15] is introduced:

$$
V_{0}=c f_{\mathrm{ctd}} A_{\mathrm{c}}+\mu N+A_{s} f_{\mathrm{yd}}\left(\mu \sin \alpha^{\prime}+\cos \alpha^{\prime}\right) .
$$

The formula above is applicable to the shear bearing capacity analysis of the beams adopting the roughening + planting bar + prestressed + building glue connection method, which is similar to the experimental models in this paper, in which the connection method of roughening + planting bar + prestressed + building glue + hooping was used. However, the formula above ignored the influence of stirrups and reinforcement ratio. Research shows that
TABle 6: Values of $c$ and $\mu$ in European code.

\begin{tabular}{lcc}
\hline Types of new-to-old concrete surface & $c$ & $\mu$ \\
\hline Very smooth & 0.025 & 0.5 \\
Smooth & 0.2 & 0.6 \\
Rough & 0.4 & 0.7 \\
Indented & 0.5 & 0.9 \\
\hline
\end{tabular}

stirrups and reinforcements play an important role in the shear resistance of the new-to-old concrete interface of the underpinning structure with flexural shear failure mode. The code [7] gives the shear calculation formula for common reinforcement:

$$
V_{S}=\beta_{s} \rho f_{\mathrm{yv}} \frac{A_{\mathrm{sv}}}{s} h_{0}
$$

To sum up, considering the effect of shear factors at the interface, the improved formula for calculating the bearing capacity of the "all-inclusive" underpinning joint is obtained:

$$
V=c f_{\mathrm{ctd}} A_{c}+\mu N+A_{s} f_{\mathrm{yd}}\left(\mu \sin \alpha^{\prime}+\cos \alpha^{\prime}\right)+\beta_{s} \rho f_{\mathrm{yv}} \frac{A_{\mathrm{sv}}}{s} h_{0},
$$

where $c$ and $\mu$ are the coefficients of the roughness of the interface; when the interface is grooved, the values of $c$ and $\mu$ are 0.4 and 0.7 (Table 6), respectively. $f_{c t d}$ is the design value of concrete tensile strength. $A_{c}$ is the shear plane area. $N$ is the axial force perpendicular to the shear plane, pressure is positive and pull is negative, and $N \leq 0.6 f_{c d} \mathrm{~A}_{c}$, When it is pulling, the value is $c f_{\mathrm{ctd}}=0 . A_{s}$ is the area of planting steel bar. $f_{\mathrm{yd}}$ is the yield strength of planting steel bar. $\alpha^{\prime}$ is the angle between the planting bar and the shear plane, i.e., $45^{\circ} \leq \alpha^{\prime} \leq 90^{\circ}$. $\beta_{s}$ is the steel correction factor; when the longitudinal reinforcement adopts HRB335 and HRB400, the value is 66. $\rho$ is the longitudinal reinforcement ratio. $A_{\mathrm{sv}}$ is the total cross-sectional area of the making stirrups. $f_{\mathrm{yv}}$ is the tensile strength design value of the making stirrups. $s$ is the stirrups spacing. $h_{0}$ is the effective height of the beam.

To verify the accuracy of equation (7), the test data in this paper are substituted into the formula, and the results are shown in Table 7. Comparing the experimental results with the theoretical calculation results, it is found that the theoretical results and the experimental results are about $2 \%$ to $6 \%$, which is within the allowable error range. To verify the accuracy of the theoretical formula further, the data of different manuscripts are substituted into equation (7). The difference between the calculated results of the manuscripts and the experimental results is small, about $2 \% \sim 13 \%$. The formula proposed in this paper has smaller error and a 
TABLE 7: Comparison of theoretical and experimental results.

\begin{tabular}{|c|c|c|c|c|c|c|c|c|c|}
\hline Data & Models & $c$ & $\mu$ & $\alpha^{\prime}$ & $\beta_{s}$ & $N_{\text {eff }}(\mathrm{kN})$ & Equation. $V_{1}(\mathrm{kN})$ & Test. $V_{2}(\mathrm{kN})$ & $V_{1} / V_{2}$ \\
\hline Test model & ZT-1 & 0.4 & 0.7 & $90^{\circ}$ & 66 & 1750 & 2587.7 & 2750.0 & 0.94 \\
\hline Numerical model & MT-1 & 0.4 & 0.7 & $90^{\circ}$ & 66 & 1750 & 2587.7 & 2652.0 & 0.98 \\
\hline \multirow{2}{*}{ Manuscript [5] } & $1: 4$ & 0.5 & 0.9 & $45^{\circ}$ & 66 & 3422 & 3821.0 & 3688.0 & 1.04 \\
\hline & $1: 2$ & 0.5 & 0.9 & $45^{\circ}$ & 66 & 7399 & 8017.5 & 7659.7 & 1.05 \\
\hline \multirow{3}{*}{ Manuscript [11] } & JD-2 & 0.4 & 0.7 & $90^{\circ}$ & 66 & 160 & 559.7 & 620 & 0.90 \\
\hline & JD-4 & 0.4 & 0.7 & $90^{\circ}$ & 66 & 80 & 467.2 & 525 & 0.89 \\
\hline & JD-6 & 0.4 & 0.7 & $90^{\circ}$ & 66 & 160 & 745.3 & 720 & 1.04 \\
\hline \multirow{4}{*}{ Manuscript [12] } & JD-5 & 0.025 & 0.5 & $90^{\circ}$ & 66 & 106 & 447.4 & 500 & 0.89 \\
\hline & JD-6 & 0.025 & 0.5 & $90^{\circ}$ & 66 & 206 & 502.7 & 575 & 0.87 \\
\hline & JD-7 & 0.025 & 0.5 & $90^{\circ}$ & 66 & 206 & 594.3 & 600 & 0.99 \\
\hline & JD-8 & 0.025 & 0.5 & $90^{\circ}$ & 66 & 395 & 708.1 & 700 & 1.01 \\
\hline
\end{tabular}

higher reliability. Therefore, the formula used to calculate the shear bearing capacity of underpinning joints with "allinclusive" pile foundation is feasible.

\section{Conclusion}

Aiming at the phenomenon of punching failure and large slip at the new-to-old concrete interface of "beam-column" underpinning joint, a new type of "all-inclusive" underpinning joint model adopting the spraying glue + grooving + planting bars + prestressed + hooping connection method is tested and numerically analyzed. The following conclusions are obtained:

(1) The failure modes of the "all-inclusive" underpinning joint are flexure-shear, and the connection method between the new-to-old concrete interfaces is reliable, which indicates that the "all-inclusive" underpinning joint adopting the spraying glue + grooving + planting bars + prestressed + hooping connection method is effective and feasible.

(2) The initial slip and the maximum slip of the damaged "all-inclusive" underpinning joint are both small, which shows that the "all-inclusive" underpinning connection method can avoid premature punching brittle failure of underpinning joint and can effectively reduce the initial slip and the overall slip at the new-to-old concrete interface.

(3) Theoretical and experimental results show that the improved calculation formula in this paper has small error and relatively accurate calculation results, which can provide a new perspective for the calculation of bearing capacity of similar projects.

\section{Data Availability}

The data used to support the findings of this study are available from the corresponding author upon request.

\section{Conflicts of Interest}

The authors declare that they have no conflicts of interest.

\section{Acknowledgments}

This research was supported by the Project of Chongqing science and Technology Committee (cstc2018jscxmsybX0167 and cstc2018jcyjAX0360), Scientific and Technological Research Program of Chongqing Municipal Education Commission (KJQN201801223, KJQN201901219, and KJQN201901207), General Program of China Postdoctoral Science Foundation (2019M663442), and Chongqing Engineering Research Center of Disaster Prevention and Control for Banks and Structures in Three Gorges Reservoir Area (SXAPGC18ZDI02, SXAPGC18ZDI0203, and SXAPGC18YB05).

\section{Supplementary Materials}

The supplementary file is part of the original data of the manuscript, corresponding to Figure 13 (load-displacement diagram), Figure 15 (abstract diagram of stirrups), and Figure 16 (abstract diagram of planting bars). The number (LOAD, D1-D8, AFTER-BEFORE, Z1-Z7) in the original data represents the position of the monitoring points, which can be viewed in Figure 8 (measuring points). In the supplementary file, LOAD represents the load under test, D1-D8 represents the displacement of underpinning beam under the corresponding load, AFTER-BEFORE represents the stirrup strain under the corresponding load, and Z1-Z7 represents the planting bars strain under the corresponding load. (Supplementary Materials)

\section{References}

[1] L. J. Ying, "Overview of underpinning technology for building foundation of subway engineering in China," Construction Technology, vol. 39, no. 9, pp. 8-12, 2010.

[2] Z. Xin, Y. Q. Xia, and J. L. Dong, "Research progress of building displacement and underpinning technology," Building Structure, vol. 46, no. 5, pp. 91-96, 2016.

[3] C. B. José, T. A. Roda, and W. C. Bracken, "Design considerations for underpinning of structures affected by karst using hydraulically driven piles," in Proceeding of the Sinkholes and the Engineering and Environmental Impacts of Karst, Huntsville, Alabama, USA, September 2003.

[4] P. F. Le, S. D. Xin, Y. D. Jun, Z. H. Hua, and L. S. Ming, "Underground underpinning technology," Mineral Exploration, vol. 6, no. 12, pp. 38-40, 2003. 
[5] G. J. He, Z. S. Ceng, K. Z. Tian, D. A. Xiong, and S. Ning, "Model test of beam-column joint for pile foundation underpinning under large axial force," Journal of Civil Engineering, vol. 37, no. 9, 2004.

[6] S. Huang, G. Xiong, and L. Haochong, "Key technology innovation of jinbin light rail foundation underpinning project," Underground Works and Tunnels, vol. 2, no. 2, pp. 7-11, 2010.

[7] X. Zhang, L. Jia, F. Xia et al., "Experimental study on mechanical behavior of frame column underpinning joints," Journal of Building Structures, vol. 32, no. 11, pp. 89-96, 2011.

[8] Q. X. Yue and X. Zhang, "Finite element analysis on mechanical behavior of column underpinning joints for building moving," Advanced Materials Research, vol. 255-260, pp. 1974-1978, 2011.

[9] Q. Xu, H. Zhu, X. Ma et al., "A case history of shield tunnel crossing through group pile foundation of a road bridge with pile underpinning technologies in Shanghai," Tunnelling and Underground Space Technology, vol. 45, pp. 20-33, 2015.

[10] Z. Li, L. Q. Ning, L. Lin, and W. X. Wei, "Experimental analysis on shear behavior of new and old concrete joint in pile foundation underpinning under large axial force," Civil Building and Environmental Engineering, vol. 37, no. S2, pp. 154-158, 2015.

[11] W. J. Wang, Study on mechanical behavior of prestressed concrete underpinning joints, Journal of Shandong Jianzhu University, vol. 5, no. 8, pp. 11-58, 2016.

[12] Q. Yue, X. Ren, and X. Zhang, "Mechanical properties of underpinning joints in structural moving: experiments and numerical modeling," The Structural Design of Tall and Special Buildings, vol. 26, no. 14, p. e1379, 2017.

[13] J.-Y. Wu and S.-L. Xu, "An augmented multicrack elastoplastic damage model for tensile cracking," International Journal of Solids and Structures, vol. 48, no. 18, pp. 2511-2528, 2011.

[14] J. Zhang, Q. Wang, and S. Hu, "Parameters verification of concrete damaged plastic model of abaqus," Building Structure, vol. 38, no. 8, pp. 127-130, 2008.

[15] European Standard, EN 1992-1-1: 2004 Euro-code2: Design for Concrete Structures-Part 1: General Rules and Rules for Buildings, European Committee for Standardization, 2004. 